Ю.І. Шевяков

Харківський національний університет Повітряних Сил ім. І. Кожедуба, Харків

\title{
МЕТОДИ ОЦІНЮВАННЯ ЛІТАКІВ ПЕРВИННОЇ ЛЬОТНОЇ ПІДГОТОВКИ ЯК БАГАТОВИМІРНИХ ОБ'ЄКТІВ 3 ВРАХУВАННЯМ ВАЖЛИВОСТІ ЇХ ОЗНАК
}

Розглянуто і розв'язано задачу вибору літака первинної підготовки із застосуванням метода мультиплікативної згортки кількісних характеристик літаків первинної підготовки та метода, заснованого на таксонометричному підході. Запропоновано модифікації иих методів шляхом врахування коефіцієнтів важливості кількісних характеристик літаків: льотні якості літака (придатність до первинного льотного навчання), безпека, економічні показники (вартість літака, вартість експлуатаиії та технічного обслуговування) та технічний супровід. У якості прикладу розглядаються шість літаків з ілюстративними даними щодо кількісних характеристик літаків.

Ключові слова: багатовимірний об'єкт, кількісні характеристики (ознаки) літаків, коефіиієнти важливості, показник якості, таксонометричний метод.

\section{Вступ}

Постановка проблеми. Актуальною задачею підвищення ефективності навчання льотного складу на сучасному етапі розвитку Повітряних Сил $є$ перехід від аутсорсінгового навчання з використанням сторонніх авіашкіл до власного самостійного первинного навчання. Головним у вирішенні цієї задачі $\epsilon$ вибір найкращого легкого літака із великої кількості літаків вітчизняного та іноземного виробництва, загальна кількість складає понад 50 зразків. Кожний зразок характеризується кількісними і якісними характеристиками, порівняння яких складає практично не вирішене завдання. Для вирішення цього завдання в статті пропонуються методи оцінювання літаків первинної льотної підготовки як багатовимірних об'єктів.

Аналіз останніх досліджень і публікацій. Коефіцієнти важливості літаків залежать від якісних і кількісних характеристик, серед яких виділимо наступні: льотні якості, безпека, економічні показники, технічний супровід. Таким чином, літак можна розглядати як багатовимірний об'єкт, який характеризується різнорідними числовими і іншими ознаками, що визначають ступінь їх впливу на ті чи інші властивості об'єкта.

Основною трудністю в задачах визначення коефіцієнтів важливості багатовимірних об'єктів є встановлення відповідної шкали оцінювання ознак об'єкта і вибір певної метрики в просторі одержуваних оцінок. Відомі підходи для подолання цих труднощів використовують різні методи агрегування i кластеризації [1-2], метод визначення коефіцієнтів важливості на основі принципу потенційного розподілу ймовірностей [3], інформаційні критерії порівняння [4-5], різні процедури багатокритеріальної оцінки [6-7]. Однак практичне застосування цих методів обмежується труднощами фізичної інтерпретації результатів оцінювання.

Одним з найбільш популярних в даний час методів впорядкування багатовимірних об'єктів і визначення їх коефіцієнтів важливості є метод аналізу ієрархій (MAI) [8-9]. Це метод формування та обробки експертних оцінок при покрокової згортки та упорядкування якісних i кількісних показників i ознак багатовимірних об'єктів дозволяє визначити числові оцінки важливості порівнюваних об'єктів. Однак більшість ознак, що характеризують такий складний об'єкт, як літак, мають чисельне значення. У зв'язку з цим виникає необхідність переходу до безрозмірних значень ознак і переведення їх значень до прийнятого для експертних оцінок діапазону значень в МAI.

Відповідний підхід був застосований в роботі [10]. Такий штучний перехід в діапазон експертних оцінок MAI фактично ускладнює процес знаходження коефіцієнтів важливості. Крім того, для проведення обгрунтованих чисельних порівнянь не можна порівнювати більш ніж 9 елементів [8], що унеможливлює порівняння достатньо великої кількості літаків.

Відомий метод, який грунтується на використанні мультиплікативної згортки відносних значень ознак багатовимірного об'єкта і який практично не залежить від кількості порівнюваних елементів [7; 11]. Але він не враховує важливість вище перелічених кількісних характеристик літаків.

Метою статті є обгрунтування методів оцінювання літаків первинної льотної підготовки як багатовимірних об'єктів на основі мультиплікативної згортки відносних значень їх ознак та таксономет- 
ричного підходу з врахуванням важливості їх кількісних характеристик.

\section{Виклад основного матеріалу}

Розглядається задача визначення коефіцієнтів важливості літаків 3 наступними значеннями їх кількісних характеристик (ознак):

$$
x^{(i)}=\left(x_{i 1}, x_{i 2}, x_{i 3}, x_{i 4}\right), \quad i=\overline{1, n},
$$

де $n$-кількість літаків щодо порівняння;

$x_{i 1}, x_{i 2}, x_{i 3}, x_{i 4}$ - чисельні значення кількісних ознак літаків, відповідно: льотної якості, безпеки, економічних показників та технічного супроводження у $i$-го літака.

Введемо штучний еталонний літак $x^{(0)}=\left(x_{01}, x_{02}, x_{03}, x_{04}\right)$, що дозволяє перевести значення ознак, які виражені в метричних шкалах відносин, в відносні безрозмірні величини наступним чином [11]:

$$
\begin{gathered}
x_{0 k}= \\
x_{0 k}^{\max }=\max _{i} \text { більше значення } k-і ̈ \text { ознаки; } \\
x_{0 k}^{\min }=\min _{i} x_{i k}, \\
\text { якщзо кращуе менше значення k-ї ознаки. }
\end{gathered}
$$

Звідси відносною величиною $k$-ї ознаки $i$-го літака буде наступне значення:

$$
\begin{aligned}
& y_{i k}= \\
& =\left\{\begin{array}{l}
\frac{x_{i k}}{x_{0 k}}, \quad \text { якщуо краще більше значення } k \text {-ї ознаки; } \\
\frac{x_{0 k}}{x_{i k}}, \quad \text { якщзо краще менше значення } k \text {-ї ознаки, }
\end{array}\right.
\end{aligned}
$$

причому $0<y_{i k} \leq 1 ; i=\overline{1, n} ; k=\overline{1,4}$.

Таким чином, чим більше відносне значення $k$-i ознаки літака, тим воно бажаніше. У якості узагальненого показника якості літака виберемо середнє геометричне значення його відносних величин [11]:

$$
z_{i}=\sqrt[4]{y_{i 1} y_{i 2} y_{i 3} y_{i 4}}, \quad i=\overline{1, n},
$$

причому $0<z_{i} \leq 1 ; \quad i=\overline{1, n}$.

Для врахування важливості ознак літака введемо модифікований узагальнений показник якості літака наступним чином:

$$
z_{i}^{(M)}=y_{i 1}^{v_{1}} y_{i 2}^{v_{2}} y_{i 3}^{v_{3}} y_{i 4}^{v_{4}}, \quad i=\overline{1, n},
$$

де

$$
v_{k}=\frac{u_{k}}{\max _{k} u_{k}}, \quad k=\overline{1,4},
$$

$u_{k}$ - показник важливості $k$-ї ознаки літака.

Нормування значень коефіцієнтів важливості ознак за співвідношенням (6) обумовлено тим, що $0<y_{i k} \leq 1 ; i=\overline{1, n} ; k=\overline{1,4}$.

Значення коефіцієнтів важливості $u_{k}$ визначені у роботі [12] і дорівнюють:

$$
u_{1}=0,60 ; \quad u_{2}=0,26 ; \quad u_{3}=0,10 ; \quad u_{4}=0,04
$$

Отже отримаємо наступні значення параметрів $v_{k}$ :

$$
v_{1}=1 ; \quad v_{2}=0,43 ; \quad v_{3}=0,17 ; \quad v_{4}=0,07
$$

Найбільше значення узагальненого показника дорівнює одиниці і досягається тільки на еталонному літаку. Отже, чим ближче до одиниці значення модифікованого показника (5), тим більшу важливість в середньому зваженому має порівнюваний об'єкт, і саме цей показник визначає значення коефіцієнта важливості літака.

Крім того, співвідношення для узагальненого показника якості (4) є частковим випадком модифікованого (5) при $v_{1}=v_{2}=v_{3}=v_{4}=0,25$, тобто в цьому випадку вважається, що ознаки літака мають однакову важливість.

Однак показники якості літаків (4) та (5) мають сенс, коли чисельні значення ї кількісних ознак більше нуля:

$$
x_{i k}>0 ; \quad i=\overline{1, n} ; \quad k=\overline{1,4}
$$

оскільки якщо, наприклад, у $i$-го літака значення хоча б однієї ознаки дорівнює нулю: $x_{i k}=0$, то $z_{i}=z_{i}^{(n)}=0$. Звідси, $i$-й літак не може бути оцінений.

В цьому випадку доцільно використовувати інший показник якості літака, який заснований на таксонометричному методі порівняння літаків, як багатовимірних об'єктів [10]. Неважко помітити, що штучний еталонний літак у відносних величинах за співвідношеннями (3) має наступний вигляд:

$$
y^{(0)}=(1,1,1,1)
$$


Отже, чим ближче за відносними значеннями ознак порівнюваний літак до еталонного, тим більше його важливість. Міру близькості порівнюваних літаків 3 еталонним визначимо наступним чином (10):

$$
\begin{gathered}
\rho_{i}=\sqrt{\left(y_{i 1}-1\right)^{2}+\left(y_{i 2}-1\right)^{2}+\left(y_{i 3}-1\right)^{2}+\left(y_{i 4}-1\right)^{2}}, \\
i=\overline{1, n} .
\end{gathered}
$$

Як і раніше, для врахування важливості ознак літака введемо модифіковану міру близькості порівнюваних літаків $з$ еталонним:

$$
\begin{gathered}
\rho_{i}^{(M)}= \\
=\sqrt{v_{1}\left(y_{i 1}-1\right)^{2}+v_{2}\left(y_{i 2}-1\right)^{2}+v_{3}\left(y_{i 3}-1\right)^{2}+v_{4}\left(y_{i 4}-1\right)^{2}} \\
i=\overline{1, n} .
\end{gathered}
$$

Протилежність напрямків зміни показників (9), (10) і висновків щодо важливості літаків $є$ незручною, тому змінимо ці співвідношення і отримаємо наступні кінцеві формули для визначення важливості літаків:

$$
\gamma_{i}=1-\rho_{i}, \quad i=\overline{1, n}
$$

- таксонометричний показник якості для оцінювання коефіцієнтів важливості літаків без врахування важливості ознак літака;

$$
\gamma_{i}^{(M)}=1-\rho_{i}^{(M)} ; \quad i=\overline{1, n}
$$

- модифікований таксонометричний показник якості для оцінювання коефіцієнтів важливості літаків 3 врахуванням важливості ознак літака, при цьому

$$
0 \leq \gamma_{i} \leq 1 ; \quad 0 \leq \gamma_{i}^{(M)} \leq 1 ; i=\overline{1, n}
$$

Найбільше значення таксонометричних показників (11), (12) дорівнює одиниці і досягається тільки на еталонному літаку. Отже, чим ближче до одиниці їх значення, тим більшу важливість має порівнюваний літак, і саме цей показник визначає значення коефіцієнта важливості літака.

Наведемо приклад порівняння шести літаків $(n=6)$ для ілюстративних даних щодо їх кількісних характеристик у вигляді наступної матриці ознак $X=\left\|x_{i k}\right\|_{6,4}$ :

$$
X=\left(\begin{array}{llll}
64 & 8 & 412 & 44 \\
82 & 7 & 328 & 50 \\
78 & 7 & 240 & 45 \\
98 & 9 & 280 & 42 \\
59 & 5 & 380 & 50 \\
62 & 5 & 310 & 40
\end{array}\right)
$$

Перетворимо елементи матриці $X$ у відносні характеристики за співвідношеннями (3), приймаючи до уваги, що для ознак, які знаходяться у першому, другому та четвертому стовпцях краще більше значення, а для ознак з третього стовпця - краще менше значення. Звідси маємо:

$$
Y=\left(\begin{array}{cccc}
0,65 & 0,89 & 0,58 & 0,88 \\
0,84 & 0,89 & 0,73 & 1,00 \\
0,80 & 0,89 & 1,00 & 0,9 \\
1,00 & 1,00 & 0,86 & 0,84 \\
0,60 & 0,56 & 0,63 & 1,00 \\
0,63 & 0,56 & 0,77 & 0,8
\end{array}\right) .
$$

Отже, коефіцієнти важливості літаків за узагальненим показником якості (4) та таксонометричним показником (11) дорівнюють відповідно:

$$
\begin{aligned}
& z_{1}=0,74 ; z_{2}=0,86 ; z_{3}=0,89 ; \\
& z_{4}=0,92 ; z_{5}=0,68 ; z_{6}=0,68 ; \\
& \gamma_{1}=0,43 ; \gamma_{2}=0,67 ; \gamma_{3}=0,75 ; \\
& \gamma_{4}=0,79 \quad \gamma_{5}=0,30 ; \gamma_{6}=0,35 ;
\end{aligned}
$$

за модифікованими показником якості (5) та (12) відповідно:

$$
\begin{aligned}
& z_{1}^{(M)}=0,56 ; z_{2}^{(M)}=0,75 ; z_{3}^{(M)}=0,75 ; \\
& z_{4}^{(M)}=0,96 ; z_{5}^{(M)}=0,43 ; z_{6}^{(M)}=0,46 ; \\
& \gamma_{1}^{(M)}=0,60 ; \gamma_{2}^{(M)}=0,79 ; \gamma_{3}^{(M)}=0,78 ; \\
& \gamma_{4}^{(M)}=0,93 ; \gamma_{5}^{(M)}=0,48 ; \gamma_{6}^{(M)}=0,52
\end{aligned}
$$

тобто рейтинги літаків майже не змінились.

Таким чином, найкращим виявився четвертий літак за всіма показниками якості. Зауважимо, що без врахування важливості кількісних характеристик третій літак виявився кращим за другий, а п'ятий та шостий отримали однакові за показниками (4) та (5), а за показниками (11) та (12) - майже однакові коефіцієнти важливості. 3 врахуванням важливості кількісних характеристик другий та третій літаки отримали однакові за показниками (4) та (5), а за показниками (11) та (12) - майже однакові коефіцієнти важливості, а шостий літак виявився кращим за п'ятий за всіма показниками. 


\section{Висновки}

1. Запропонований метод вибору літака первинної підготовки із застосуванням мультиплікативної згортки його кількісних характеристик.

2. Запропонований модифікований узагальнений показник якості літака, який враховує коефіцієнти важливості його кількісних характеристик.

3. Запропоновані показники із застосуванням мультиплікативної згортки кількісних характеристик ознак літака не придатні, якщо хоча 6 одна 3 ознак є нульовою.
4. Запропоновані таксонометричний метод та його модифікація щодо вибору літака первинної підготовки, які можна застосовувати для будь-яких невід'ємних кількісних ознак літаків.

5. Порівняння результатів оцінки літаків за методами мультиплікативної згортки та таксонометричних методів для ілюстративного прикладу показав майже незмінність рейтингів літаків.

6. Запропоновані методи дозволяють порівнювати літаків первинної підготовки практично для будь-якої їх кількості.

\section{Список літератури}

1. Курсиков Н.И. Метод агрегирования многомерных данных / Н.И. Курсиков, Б.Д. Лебедев // Информационные технологии. - 2003. - № 2. - С.40-42.

2. Буравлёв А.И. Оценка качества объектов по неметризуемому вектору характеристик / А.И. Буравлёв, В.С. Брезгин // Вооружение и экономика. - 2009. - № 1(5).- С. 26-29.

3. Ташевский А.Г. Метод определения коэффициентов соизмеримости образцов новой техники машиностроения на основе принципа потенциального распределения вероятности / А.Г. Ташевский // Инструмент.- 2011. - № 31. - С. 74-80.

4. Akaike H. Information theory and an extension of the maximum likelihood principle / H. Akaike, B.N. Petrov, F. Csáki // 2nd International Symposium on Information Theory, Tsahkadsor, Armenia, USSR, September 2-8, 1971. Budapest: Akadémiai Kiadó.

5. Айвазян С.А. Прикладная статистика. Классификация и снижение размерности / С.А Айвазин., И.С. Енюков, А.В. Мешалкин. - М.: Финансы и статистика, 1989. - 471 с.

6. Емельянов С.В. Многокритериальные методы принятия решений / С.В. Емельянов, О.И. Ларичев. - М.: Знание, 1985. $-32 \mathrm{c}$.

7. Ногин В.В. Принятие решений в многокритериальной среде: количественный подход / В.В. Ногин. - М.: Физматлит, 2005. - 269 с.

8. Саати Т. Аналитическое планирование. Организация систем: пер. с англ. / Т. Саати, К. Кернс. - М.: Радио и связь, 1991. -224 с.

9. Кушнерук Ю.І. Використання методу аналізу ієрархій для оцінювання пріоритетів структурних частин та підрозділів внутрішніх військ під час розв'язання задач розподілу обмежених ресурсів / Ю.І. Кушнерук, В.П. Василенко, В.Г. Дундуков // Честь і закон: Науковий журнал АВВ МВС України. - 2013. - № 2(45). - С. 56-62.

10. Городнов В.П. Теоретические основы моделирования микроэкономических и других процессов: монография / В.П. Городнов. - Х.: Аккад. ВВ МВД Украины, 2008. - 484 с.

11. Кононов В.Б. Методы определения коэффициентов важности боевых средств / В.Б. Кононов, Ю.И. Кушнерук, О.В. Коваль // Системи озброєння і військова техніка. - 2012. - № 3(31). - С. 39-41.

12. Шевяков Ю.І. Вибір літака первинної підготовки за методом аналізу ієрархій / Ю.І. Шевяков // Системи озброєння і військова техніка. - 2020. - №3(63). - C.112-117. https://doi.org/10.30748/soivt.2020.63.16.

\section{Відомості про автора:}

\section{Шевяков Юрій Іванович}

доктор технічних наук доцент директор Інституту цивільної авіації Харківського національного університету

Повітряних Сил ім. І. Кожедуба,

Харків, Україна

https://orcid.org/0000-0002-5322-6674

\section{Information about the author:}

\section{Iurii Sheviakov}

Doctor of Technical Sciences Associate Professor

Director of the Civil Aviation Institute

of Ivan Kozhedub Kharkiv

National Air Force University,

Kharkiv, Ukraine

https://orcid.org/0000-0002-5322-6674 


\title{
МЕТОДЫ ОЦЕНКИ САМОЛЕТОВ ПЕРВИЧНОЙ ЛЕТНОЙ ПОДГОТОВКИ КАК МНОГОМЕРНЫХ ОБЪЕКТОВ С УЧЕТОМ ВАЖНОСТИ ИХ ПРИЗНАКОВ
}

\author{
Ю.И. Шевяков
}

Рассмотрены и решена задача выбора самолета первичной подготовки с применением метода мультипликативной свертки количественных характеристик самолетов первичной подготовки и метода, основанного на таксонометрическом подходе. Предложены модификации этих методов путем учета коэффициентов важности количественных характеристик самолетов: летные качества самолета (пригодность к первичному летного обучения), безопасность, экономические показатели (стоимость самолета, стоимость эксплуатации и технического обслуживания) и техническое сопровождение. В качестве примера рассматриваются шесть самолетов с иллюстративными данными о количественных характеристик самолетов.

Ключевые слова: многомерный объект, количественные характеристики (признаки) самолетов, коэффициентыл важности, показатель качества, таксонометрических метод.

\section{METHODS OF EVALUATION OF PRIMARY FLIGHT TRAINING AIRCRAFT AS MULTIDIMENSIONAL OBJECTS, TAKING INTO ACCOUNT THE IMPORTANCE OF THEIR FEATURES}

\section{Shevyakov}

The problem of choosing a primary training aircraft using the method of multiplicative convolution of quantitative characteristics of the primary training aircraft and the method based on the taxonomic approach is considered and solved. Modifications of these methods are proposed taking into account the coefficients of importance of quantitative characteristics of aircraft: flight quality (suitability for initial flight training), safety, economic performance (aircraft cost, cost of operation and maintenance) and maintenance. The modification of the multiplicative convolution is defined as the geometric mean weighted value. The modification of the taxonomic index is proposed as a weighted sum of quadratic deviations in the Euclidean metric. Determining the coefficients of importance of quantitative characteristics is proposed by the method of analysis of hierarchies. A modified generalized indicator of aircraft quality is proposed, which takes into account the coefficients of importance of its quantitative characteristics. The taxonomic method is proposed to be used in cases where at least one of the quantitative characteristics of the primary aircraft is zero. As an example, we consider six aircraft with illustrative data on the quantitative characteristics of aircraft. A comparison of the results of aircraft evaluation using multiplicative convolution methods and taxonomic methods for an illustrative example showed almost unchanged aircraft ratings. The proposed methods allow to compare primary training aircraft for almost any number of them.

Keywords: multidimensional object, quantitative characteristics (features) of aircraft, coefficients of importance, quality index, multiplicative convolution of quantitative characteristics, taxonomic method. 